\title{
Barnacle larval transport in the Mandovi-Zuari estuarine system, central west coast of India
}

\author{
Grinson George $\cdot$ Dattesh V. Desai $\cdot$ \\ Chetan A. Gaonkar - V. M. Aboobacker • \\ P. Vethamony $\cdot$ Arga Chandrashekar Anil
}

Received: 25 October 2012/Revised: 4 June 2013 / Accepted: 16 June 2013/Published online: 30 June 2013

(C) The Oceanographic Society of Japan and Springer Japan 2013

\begin{abstract}
A two-dimensional hydrodynamic and particle tracking model was used to estimate the dispersion and retention of barnacle larvae from their possible spawning sites in a tropical monsoon-influenced estuarine system (central west coast of India). Validation of the hydrodynamic simulations yielded a good match with field measurements. The pattern of larval dispersal in the region varied with the winds and currents. The seasonal changes in abundance could be attributed to physical forcing and weather conditions. The extent of barnacle larval dispersal from spawning sites varied from 10 to $78 \mathrm{~km}$ for different sites and seasons. During a 24-h cycle, the larval abundance showed one to two peaks in the estuarine area. The increased larval abundance is favored by the flood currents, pushing the larvae into the estuary. Physical forcing in the region helps in transport of the larvae from their spawning sites hugging to the coast and contributing to the population within the estuary. Field observations and numerical experiments suggest the occurrence of higher larval abundance in the estuary during post-monsoon. The dispersal pattern indicated that the barnacle population present in the estuary is well mixed, and with a seasonally changing pattern.
\end{abstract}

Keywords Numerical modelling - Barnacle larvae . Hydrodynamics · Estuary · Dispersion and retention

\footnotetext{
G. George $(\bowtie)$

Indian Council of Agricultural Research, Central Marine

Fisheries Research Institute, Kochi, India

e-mail: grinsongeorge@yahoo.co.in

D. V. Desai · C. A. Gaonkar · V. M. Aboobacker .

P. Vethamony · A. C. Anil

Council of Scientific and Industrial Research, National Institute

of Oceanography, Panjim, Goa, India
}

\section{Introduction}

Mandovi-Zuari is one of the major estuarine systems of the central west coast of India. Barnacles are found in large numbers in the intertidal areas along the boundaries of this estuary and biofouling by barnacles poses a major threat to navigation, fishing, tourism and port-related activities in this estuarine system (Desai and Anil 2005; Desai et al. 2006). Balanus amphitrite Darwin is a dominant intertidal and fouling barnacle in the Mandovi-Zuari estuarine system (Anil 1986; Desai and Anil 2005). The life cycle of many fouling and benthic suspension feeding organisms includes a pelagic larval phase important in dispersal. The key factor that influences the final destination of the larvae during dispersal is their planktonic larval duration (PLD) phase, which depends on both genetic and environmental variables (Anil and Kurian 1996; Anil et al. 2001; Desai and Anil 2004) The PLD phase of barnacles is 6-10 days and, on completion of their PLD phase (6-10 days), the larvae settle down if a suitable hard substratum is available, otherwise they will continue their PLD phase in search of a viable substratum and finally perish if they fail to settle on one (Gaines and Bertness 1992; Seed and Suchanek 1992). A characterization based on the quantity of food, temperature, salinity, dissolved oxygen, etc. during planktonic larval life indicates its approximate duration (Anil and Kurian 1996; Anil et al. 2001; Desai and Anil 2004; Desai and Prakash 2009).

A sufficient retention time in an estuarine basin could trap larvae (Lobel and Robinson 1986), zooplankton (Boicourt 1982; Sammarco and Andrews 1988, Murdoch 1989; Thiebaut et al. 1994), phytoplankton (Roff et al. 1979) or neutrally buoyant material (Wolanski and Hamner 1988; Black et al. 1990). The pelagic larval phase of barnacles is responsible for their dispersion or retention, 
because during this phase the hydrodynamic forcing on the larvae exceeds its swimming ability (Chia et al. 1984; James et al. 2002; Cowen et al. 2006; Aiken et al. 2007). Thus, the factors such as larval sinking rate, larval swimming speed, and the direction and velocity of ambient currents play a major role in their dispersal. Environmental (e.g. salinity and temperature) or biological (e.g. availability and quality of sestonic food or predation) factors are imperative in their survival and influence the length of the larval life. The dispersion of larvae critically depends on ambient currents, as the magnitude of currents is often larger than their swimming or sinking velocities.

The scales of relevance, in both time and space, are very broad and may include the effects of turbulent diffusion, tides, storm-mixing events and wind-driven currents, internal waves, meso-scale eddies and large-scale general circulation (Okubo 1994). The circulation pattern in the north Indian Ocean is influenced by seasonally reversing monsoon winds (Shetye et al. 1991). Transfer of water masses between the Bay of Bengal and the Arabian Sea ensues due to an eastward summer monsoon current (SMC) during the southwest (SW) monsoon and a westward winter monsoon current (WMC) during the northeast (NE) monsoon (Shankar and Shetye 2001). Currents along the west coast of India are dominated by tides, which are mixed with dominant semi-diurnal constituents (Unnikrishnan et al. 1999). The tidal range increases from south to north due to the broadening of the continental shelf (Kunte et al. 2000).

In estuaries, freshwater is mixed with seawater by the action of tides, wind effects and other physical processes. Density differences between seawater and river water may also result in horizontal pressure gradients, which affect the flow pattern (Dyer 1979). Concerning larval dispersion in estuaries, the most important physical feature (in both salt wedge and partially mixed estuaries) is that the bottom water has a net movement landward and the surface water a net movement seaward when averaged over a number of tides.

Larval longevity and water movement establish the potential for dispersal, whereas larval behavior often determines the actual degree of spread. Two independent methods have been employed to estimate the quantitative relationship between the duration of the pelagic period and the scale of dispersal. Extensions of geographic ranges in species with pelagic larvae and sedentary or sessile adults suggest that a 10- to 15-day larval period results in a spread of over 20-30 km (Kinlan and Gaines 2003; Kinlan et al. 2005; Palumbi 2003). This is in agreement with oceanic diffusion measurements and suggests a positive correlation between time and spread. It has been indicated that several hours of larval period result in a spread of the order of hundreds of meters, 1-2 days allow dispersal of approximately $1 \mathrm{~km}$, a week or two increases the scale to $10 \mathrm{~km}, 1-2$ months correspond to $100 \mathrm{~km}$ and a year can result in movements of $1,000 \mathrm{~km}$ (Shanks 2009). Significantly greater dispersal requires a substantially longer pelagic period.

In the present work, we studied larval retention and dispersal at the confluence of the estuary with the sea. This study was motivated by the member-vagrant hypothesis that the larval dispersion and retention pattern in the region is maintained by the areas (geographical and hydrodynamic) that limit the dispersal and advection of larvae during the PLD phase. No study has so far been carried out on the central west coast of India to determine the influence of geographic and hydrodynamic limitations on dispersal or retention of barnacle larvae. The focus is to find out whether the abundant barnacle population in the Mandovi-Zuari estuarine system is the manifestation of a closed group trapped by the hydrodynamic or geographical limitation. This has been attempted using an Eulerian hydrodynamic model as well as a Lagrangian particle analysis model to simulate the barnacle larval transport. Larvae were released as inert conservative particles from their representative spawning sites under a range of hydrodynamic conditions unique to the estuary in order to simulate spreading and weathering of larvae under the influence of prevailing flow and associated dispersion processes.

Utilization of high resolution biophysical models to estimate dispersal distance or retention is advantageous as the models allow multiple releases of virtual larvae, thus making each individual simulation equivalent to an isolated measurement of a dispersal event. These simulations provided opportunities for repeated experiments through time and space on expected variability in hydrodynamics and allowed the construction of a connectivity matrix (Cowen and Sponaugle 2009). The scale and predictability of larval dispersion and retention remains unknown largely due to the difficulty in measuring larval dispersion in open estuarine environments. Numerical modelling provides a solution for this as the hydrodynamics and particle transport can be simulated to near-real values for a large domain at fine resolutions, enabling us to carry out more experiments on larval dispersion and retention in open estuarine environments. We validated the modelled larval dispersion using field data. We identified suitable times and locations for larval dispersal and settlement, and accordingly calculated the maximum and minimum distances the larvae can disperse in different seasons.

\section{Materials and methods}

\subsection{Study area and model domain}

The study region (Dona Paula bay in the Zuari estuary, $15^{\circ} 26^{\prime} 18.44^{\prime \prime} \mathrm{N}, 73^{\circ} 47^{\prime} 53.9^{\prime \prime} \mathrm{E}$ ) is located along the central 
west coast of India. Figure 1 shows the study area and model domains. Model domains were set up with coarse and fine resolution rectangular Cartesian grids of $500 \times 500 \mathrm{~m}$ and $50 \times 50 \mathrm{~m}$ spacing, respectively. Bathymetry data obtained from MIKE-CMAP and the Naval Hydrographic Office (NHO) chart have been linearly interpolated to each grid in the model domain. The coarse resolution domain extends 110 and $140 \mathrm{~km}$ in the $X$ and $Y$ directions, respectively. The main purpose of this modelling is to study the larval dispersion along the open coast. However, this coarse domain is inadequate to resolve some specific details at certain areas, especially in the estuary. Hence, a fine resolution domain, which extends 13 and $14 \mathrm{~km}$ in the $X$ and $Y$ directions, respectively, has been considered within the larger domain to simulate hydrodynamics and larval transport in the study region.

\subsection{Hydrodynamic modelling}

Few models have exposed the hydrodynamics of these areas. Shetye and Murty (1987) used a one-dimensional numerical model to study the annual salt budget in the Zuari. Shetye et al. (1995) found that the momentum balance in these estuaries is primarily between the pressure gradient and friction. Unnikrishnan et al. (1997) developed a 1D network numerical model for the entire estuarine system including all the tributaries to study the decay of the tidal elevation in the upstream regions of these estuaries during the monsoon season. The mean downstream velocity associated with the freshwater influx is sufficiently large to prevent upstream propagation of tides, thereby causing the decay. As the maximum depth of the coastal region considered in the model is less than $15 \mathrm{~m}$, we have used a 2D model.

In order to simulate the tidal elevations and flows in the study area, a depth-averaged two-dimensional hydrodynamic model, MIKE $21 \mathrm{HD}$, developed by DHI Water \& Environment, Denmark, has been used (DHI 2001). Surface elevation and current velocities are calculated by solving dynamic and vertical integrated equations of continuity and conservation of momentum in $X$ and $Y$ directions. This model has been used before to study the flow characteristics at various coastal and estuarine regions (Babu et al. 2005; Chubarenko and Tchepikova 2001).

There are three open boundaries for the coarse model domain: the west boundary is between Karwar and Vengurla, the south boundary is perpendicular to Karwar and the north boundary is perpendicular to Vengurla. The tidal elevation measurements carried out for the above period were not sufficient to force the model at the open boundary for a longer period. In order to achieve this forcing, the amplitude and phase of major tidal constituents were derived. The tidal range in the Mandovi and Zuari estuaries is about $2.0 \mathrm{~m}$. M2 (principal lunar semi-diurnal constituent) is the dominant constituent in these estuaries. The amplitude of M2 is about $55 \mathrm{~cm}$, which is three times higher than the $\mathrm{S} 2$ (principal solar semidiurnal constituent). The dominant diurnal constituents are K1 (luni-solar declinational) and O1 (lunar declinational) (Manoj and Unnikrishnan 2009). Tidal elevations at Karwar and Vengurla have been predicted using these tidal constituents provided by the International Hydrographic Bureau (Anonymous 1930) and applied at the south and north boundaries, respectively. The tidal elevations between Karwar and Vengurla are linearly interpolated to each grid of the west boundary.

Tidal elevations and fluxes from the coarse model were extracted at the boundaries of the fine resolution model domain and applied as boundary conditions to simulate the tidal elevations and flows in the fine resolution model domain. In both coarse and fine model domains, apart from the tides, wind data measured at Dona Paula (Goa) coastal station using an automatic weather station (AWS) were also applied as input for the simulations. Wind data measured at $43.5 \mathrm{~m}$ height were reduced to $10 \mathrm{~m}$ height using the power law-a method for extrapolating the wind speeds between two heights (Peterson and Hennessey 1978). Winds are assumed to be uniform over the whole domain. As wind speeds from National Centers for Environmental Prediction (NCEP) are in the coarse grid $\left(2.5^{\circ} \times 2.5^{\circ}\right)$, AWS winds were applied over the entire model domain.

During model simulation, the time step interval for the simulation has been selected in such a way that it should satisfy the stability criterion. Time steps of 20 and $15 \mathrm{~s}$ were considered in the coarse model and fine model, respectively. The corresponding Courant numbers are 1.7 and 3.6, respectively. The calibration parameters applied in the simulations after tuning the model are eddy viscosity, bed resistance and the wind friction factor. A velocitybased Smagorinsky scheme $\left(C_{\mathrm{s}}\right)$ with a constant value of $0.5 \mathrm{~m}^{2} \mathrm{~s}^{-1}$ has been applied to calculate the eddy viscosity. A Manning number of $32 \mathrm{~m}^{1 / 3} \mathrm{~s}^{-1}$ has been considered as the calibration parameter for the bed resistance. The wind friction factor is taken as 0.0026 .

The simulated tidal elevations and current velocities have been validated with predicted tidal elevations and measured currents (a recording current meter mooring location is marked in Fig. 1b). The mooring depth is $6 \mathrm{~m}$. Currents are measured for every 10-min interval using the meter (model RCM7; Aanderaa, Norway) during 14 November-10 December, 2007. The current speed and direction was resolved into $\mathrm{u}$ - and v-velocity components representing currents in the east-west direction (east is considered as positive and west as negative) and in the north-south direction (north is considered as positive and south as negative), respectively. Calibration problems were 
Fig. 1 a Study area showing the large domain with spawning sites and $\mathbf{b}$ small domain with recording current meter mooring location and major sites discussed in the text
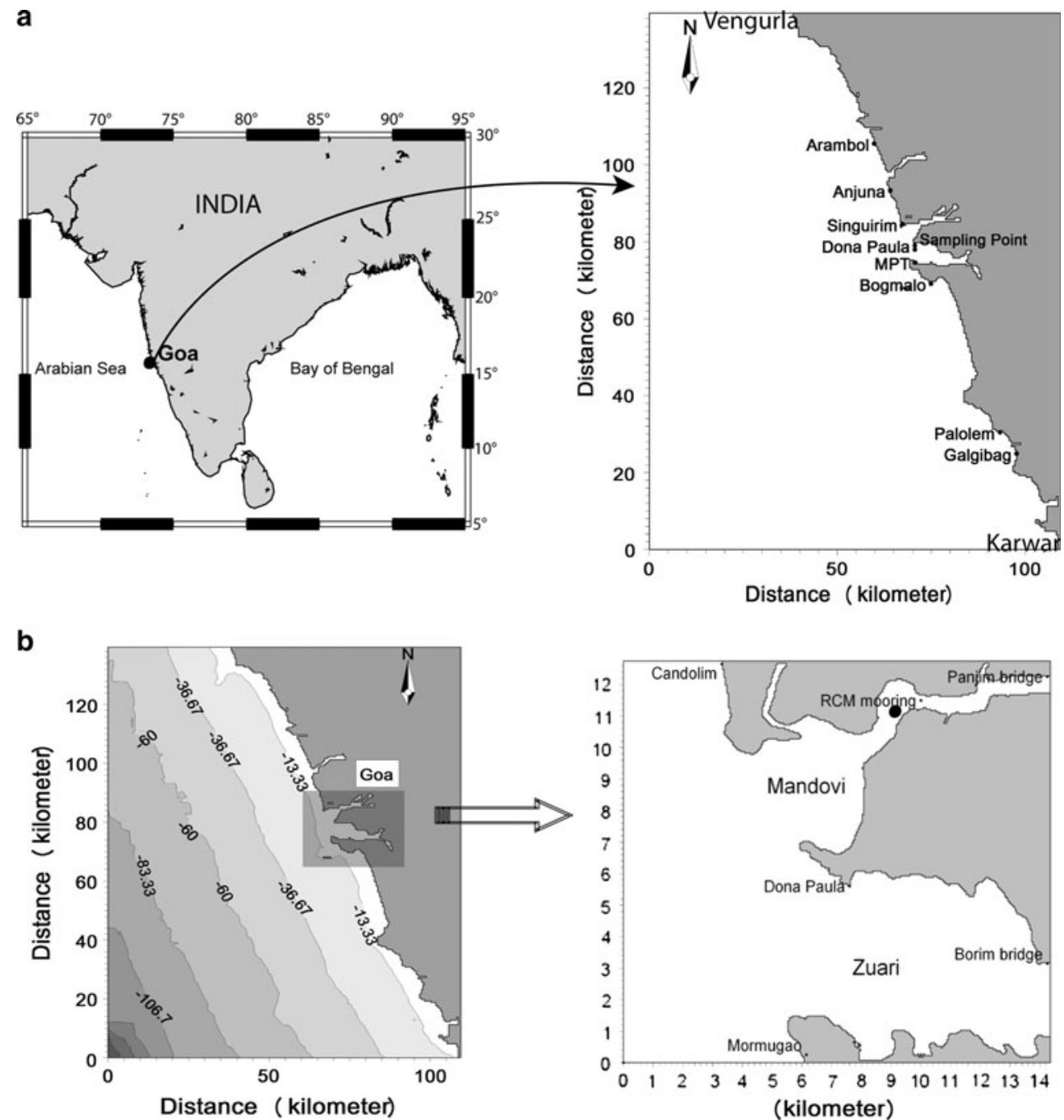

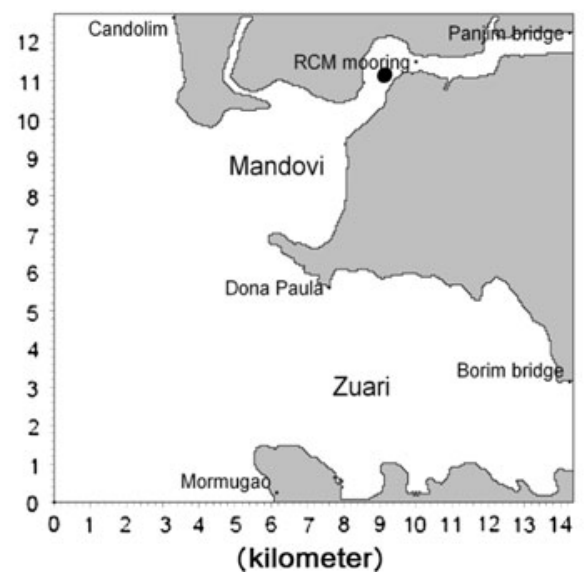

observed while matching the simulation results along the narrow channel, where the flow speed is difficult to achieve in comparison with the mouth of the estuary, with the measurements. This problem was overcome by applying friction factors to the model, and the model was calibrated with observed currents at one location. This calibrated model has been used to simulate flow patterns during three different periods: December 2006 and May and October 2007.

\subsection{Larval transport modelling}

The particle analysis (PA) module of the MIKE 21 (DHI 2001) has been used to simulate the larval transport. The model simulates the transport and fate of dissolved and suspended substances in the aquatic environment under the influence of fluid transport and associated dispersion processes. Hydrodynamic modelling (HD module) is the basic requirement for the larval transport modelling (PA module). The PA module takes the input from the HD module.
It uses the Lagrangian random-walk technique to track the movement of the particles released, and the same can be effectively utilized for tracking the retention or dispersion of hypothetical larvae released within the domain (Stephens et al. 2006; George et al. 2011; Chetan Gaonkar et al. 2012).

In the present study, for the simulation of barnacle larval transport, the following assumptions/factors were imposed:

1. Period of simulation: based on the previous studies on barnacles in the same region, the PLD phase is approximated as 10 days for the present study, after which they are treated as settled (Anil and Kurian 1996; Anil et al. 2001; Desai and Anil 2004; Desai and Prakash 2009).

2. Total particles released: one particle is assumed to be equivalent to 1,000 larvae as it is difficult to model larval transport with a large number of particles. At each time step, 4,000 larvae were released equivalent to 11.92 million hypothetical larvae over 2,980 time steps (with a time step interval of $30 \mathrm{~s}$ ). 
3. Particle size of released larvae: release is continued for $24 \mathrm{~h}$ and 50 min covering 2 tidal cycles as the source flux. Assuming a mass of $5 \mu \mathrm{g}$ for each larva, $0.2 \mathrm{mg}$ of larvae per second was released in each time step. The estimated time of hatch was controlled using a uniform source flux defining the mass and release of larvae.

4. The simulations have been carried out for 15 days duration in each of the season, considering the release of larvae on the 6th day, and the larval transport was observed for the next 9 days after the release. Larvae are defined as neutrally buoyant, and they follow the prevailing flow without being settled.

5. Dispersion of the larvae has been analyzed for each season. The dispersal patterns at the beginning (after complete release of the larvae), middle and end of the simulation have been plotted to visualize the larval dispersion. The concentration, i.e. the number of hypothetical larvae for each unique hydrodynamic situation has also been extracted at various sampling stations to assess the intensity of retention or dispersal under the influence of flow and associated dispersion processes.

6. The larval abundance in a region is affected by predation, mortality and behaviour (Fiksen et al. 2007). In this study, these aspects were neglected, as the variation in these parameters in the study domain is not known, and it is difficult to interpolate them in spatial scales in the numerical model. Turbulent tidal transport has no effect on barnacle nauplii and cyprids compared to larval forms of mollusks (veligers) (Jessopp 2007). Particles that reach the open boundaries or hit land before the end of the 10 days are deducted from the model domain.

7. The larvae have been released based on the nature of the site as barnacle spawning takes place only in rocky areas and areas with a hard substratum.

\subsection{Spawning sites}

The spawning sites for larval release were selected on the basis of an exploratory survey conducted in the study site. The spawning sites are Vengurla, Arambol, Anjuna, Singuirim, Dona Paula, MPT (Mormugao Port), Bogmalo and Galgibagh (Fig. 1a). The spawning sites were selected based on visual observations on the occurrence of barnacles in the intertidal rocky habitat and represented the spawning areas.

\subsection{Larval sampling}

Larval samples were collected from the sampling point near Dona Paula (Fig. 1a) on an hourly basis for a period of
$24 \mathrm{~h}$ during 3 different sampling periods (December 2006 and May and October 2007), as representatives of 3 different seasons, namely NE monsoon, pre-monsoon and post-monsoon. A detailed explanation about the seasons has been provided in Sects. 3.3.1 to 3.3.3. The October 2007 (post-monsoon) field sampling was carried out at the beginning of the month during which the reversal of the monsoonal wind occurs.

Samples were collected using a Haron-Trantor net of mesh size $100 \mu \mathrm{m}$. The net was towed horizontally with the help of a boat for about $10 \mathrm{~min}$. The volume of water filtered was calculated using the number of revolutions obtained with a flow meter. The samples were preserved in $5 \%$ formaldehyde and later sorted and counted under a dissection microscope to determine their abundance.

\subsection{Data analysis}

Data on barnacles which were collected during different months were log-transformed to ensure normality of means and homogeneity of variances before statistical analysis. The log-transformed data were then subjected to two-way analysis of variance (ANOVA) to evaluate the variance in larval abundance during different sampling hours, and tidal height.

\section{Results}

\subsection{Field observation of larval abundance:}

Larval abundance was highest during October 2007 (Fig. 2). The abundance significantly differed between all three sampling periods (ANOVA, $p \leq 0.0005$ ). There was an hourly variation in the larval abundance during the May 2007 and October 2007 samplings. During the December 2006 sampling, larval abundance peaked between 2330-0230 hours with a non-significant variation between different sampling hours (ANOVA, $p \geq 0.05$ ). During the May 2007 sampling, more larvae were observed during the early morning hours (0230-0830 hours) with significant variation between different sampling hours (ANOVA, $p \leq 0.05$ ). During the October 2007 sampling, two peaks in larval abundance were observed between 1730 and 0130 hours. Analysis of variance also showed a significant variation between different sampling hours (ANOVA, $p \leq 0.05$ ) during this sampling period. The number of cyprids in the study region was smaller compared to the nauplii.

\subsection{Hydrodynamics of the study region}

Model results have been validated with measurements carried out during 14 November-10 December 2007 
Fig. 2 Barnacle larval abundance during field study: a NE monsoon, b pre-monsoon and $\mathbf{c}$ post-monsoon seasons
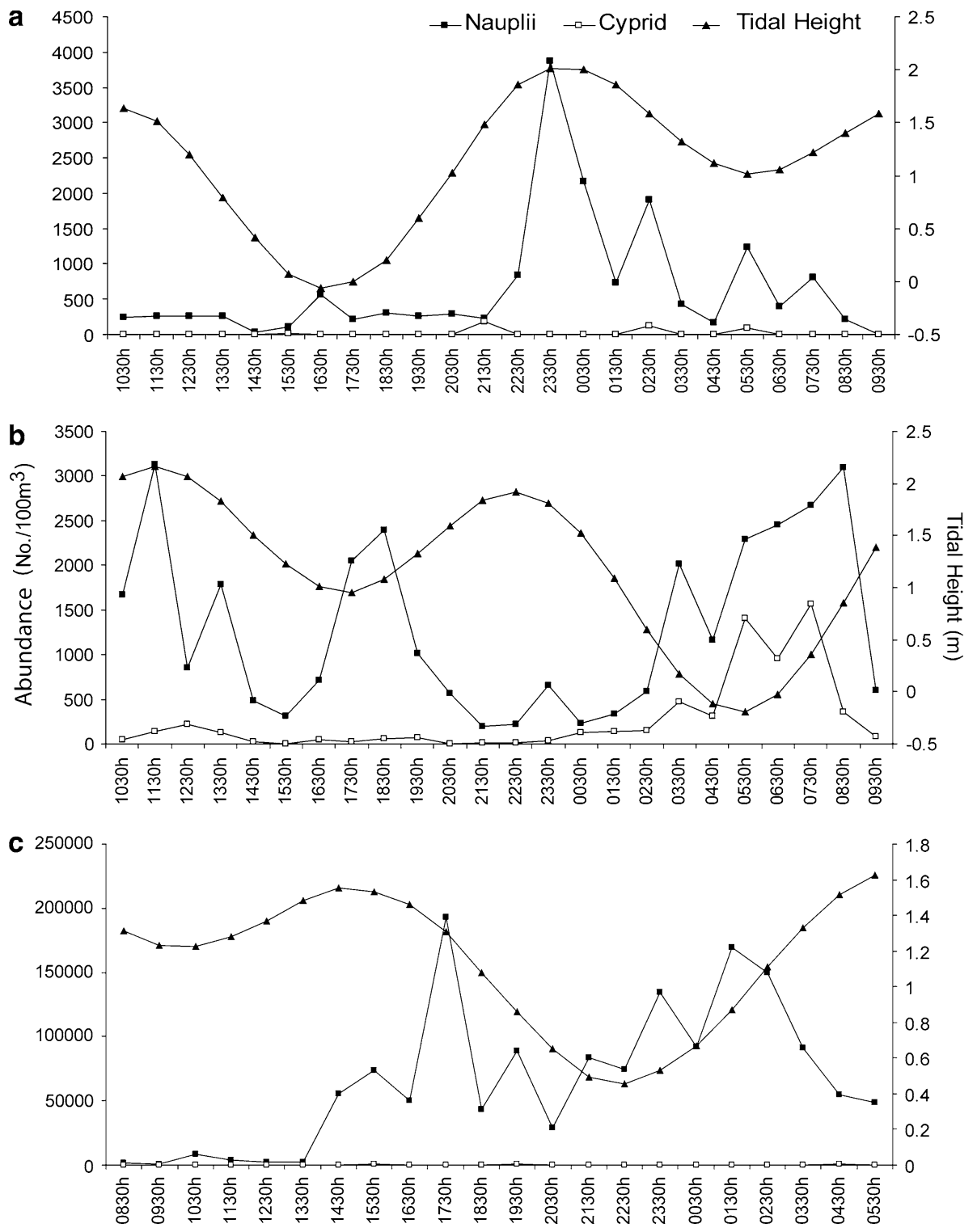

(Fig. 3a-c). The modelled $u$ - and $v$-velocities show good match with the measured current velocities (Fig. 3a, b). The modelled and predicted tidal elevations (Fig. 3c) show a good match with no phase difference. Correlation coefficients of 0.71 and 0.68 have been obtained between the measured and modelled $u$ and $v$ velocities, respectively. A slight over-estimation of the modelled $u$-velocity has been noticed, with a bias of $0.16 \mathrm{~ms}^{-1}$. The modelled $v$-velocity is slightly under-estimated, with a bias of $-0.06 \mathrm{~ms}^{-1}$. The root mean dquare error calculated for $u$ and $v$ velocities are 0.37 and $0.14 \mathrm{~ms}^{-1}$, respectively.

The coastal circulation indicates that the flow along the Goa coast is towards the north while flooding and towards the south while ebbing, with a prominent southward drift during the pre-monsoon and NE monsoon seasons. However, during the post-monsoon season, the prominent drift is towards the north. In the Mandovi estuary, the flow is towards the east while flooding and towards the west while ebbing. The tidal currents play a major role in the crossshore movement of the particles in the estuarine system. However, small-scale tidal eddies also influence the dispersion characteristics inside the estuaries. The flow is relatively stronger inside the Mandovi River. The maximum current speeds in the study area during flooding are 0.96, 0.88 and $0.70 \mathrm{~ms}^{-1}$ during the pre-monsoon, post-monsoon and NE monsoon seasons, respectively, whereas they are $0.89,1.08$ and $0.65 \mathrm{~ms}^{-1}$, respectively, while ebbing. The maximum current speeds inside the Zuari estuary (at the larval sampling point) while flooding are 0.3, 0.63 and $0.12 \mathrm{~ms}^{-1}$ during the pre-monsoon, post-monsoon and NE monsoon seasons, respectively, whereas they are $0.33,0.39$ and $0.20 \mathrm{~ms}^{-1}$, respectively, while ebbing. Currents in the 
a

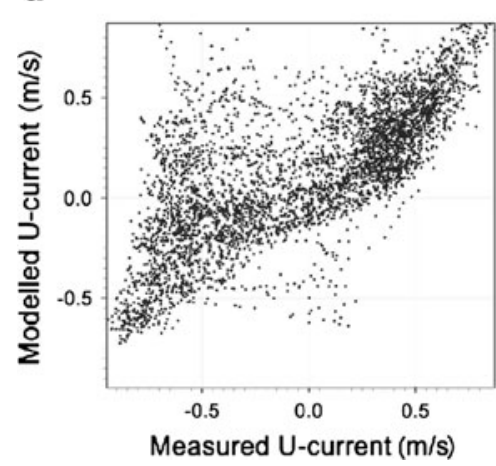

b

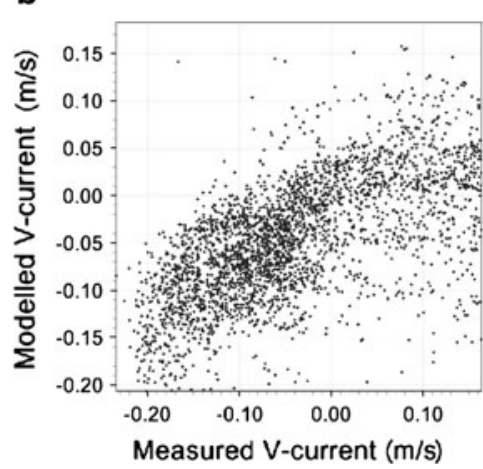

C

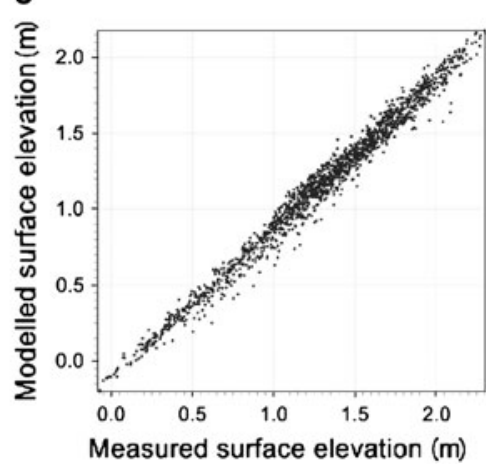

Fig. 3 Comparison between modelled and measured a surface elevation, $\mathbf{b}$ current speed and $\mathbf{c}$ direction

estuary tend to disperse the larvae, but features like eddies and geographical limitations tend to retain them.

\subsection{Larval dispersion and retention as envisaged} in the numerical simulation:

The results of simulation carried out in the large domain were analysed to assess the larval dispersion from the possible spawning locations and to calculate the number of larvae reaching the sampling point. The extent of larval dispersion is influenced by the winds, tides and currents of the respective season as described below. This could be the reason for the low larval abundance in the Zuari estuary during this season. The larvae released by the local population (Dona Paula and Mormugao spawning grounds) were retained only at the field sampling site.

\subsubsection{NE monsoon season}

Though tide-generated currents are dominant, NE winds do have a role in the larval transport during December. A net southward flow along the coast has been simulated for the particle transport from all the spawning locations (Fig. 4). However, the quantum of particles reaching the sampling point, which is the same as the station used for field sampling at the Zuari estuary, is in the decreasing order from Arambol to MPT. No particles released at the locations to the south of MPT reached the sampling point in the Zuari estuary. This also coincides with low larval abundance in the Zuari estuary. We observed a net off-shore particle transport off Singuirim and Dona Paula due to NE winds supported by tidal currents. For the spawning locations south of Singuirim, major amounts of particles aggregated along the coastal belt south of Bogmalo.

\subsubsection{Pre-monsoon season}

A sea breeze is prevalent along the west coast of India during the pre-monsoon season (Aparna et al. 2005) and it has significant impact on the diurnal cycle of the sea-state off Goa (Neetu et al. 2006). During May, the predominant winds are from the northwest and the magnitude is of the order of $5-8 \mathrm{~ms}^{-1}$. This results in a frequent and intense movement of particles in a southward direction and, hence, the particles are widely spread southwards in comparison to December (Fig. 5). The magnitude of the southward spread of particles is in the increasing order from Arambol to Galgibagh (Table 1). However, the quantum of particles reaching the sampling point at the Zuari estuary is in the increasing order from spawning locations at Anjuna, Singuirim and Arambol. There is no effect in the sampling point at the Zuari estuary for the particles released at other locations.

\subsubsection{Post-monsoon season}

During the first half of October, there exist southwest (SW) winds with low magnitude due to the retrieval of the SW monsoon. However, during the second half of the month, NE winds prevail due to the onset of the NE monsoon and the particle movement will be northwards. The field sampling and simulations took place during the first half of October during which the reversal of the monsoonal wind occurs. The effect of the retrieval of the monsoon is a gradual process and the selected time period illustrates this. Therefore, in October, dispersal of particles predominantly occurs northwards (Fig. 6). The particles reaching inside the Zuari estuary are fewer in the post-monsoon season than in other seasons, and accumulation is near the mouth of the estuarine system. The quantum of particles reaching the sampling point at the Zuari estuary is in the increasing order from spawning locations at MPT, Bogmalo and Dona Paula and this was observed by larval abundance at the field sampling site and the larval abundance is at its peak during this season compared to other seasons.

There is spatial and temporal variation in the larval dispersal pattern from different spawning sites. The coastal 


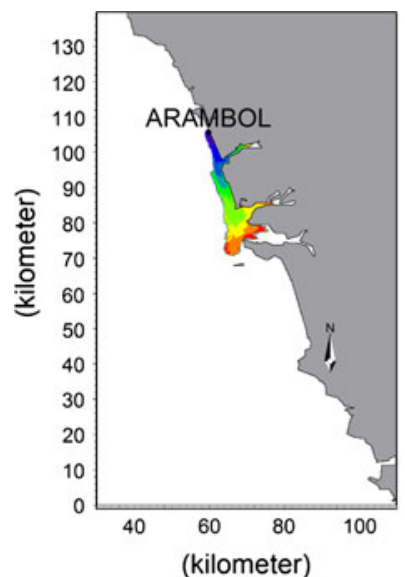

12/20/2006 00:00:00

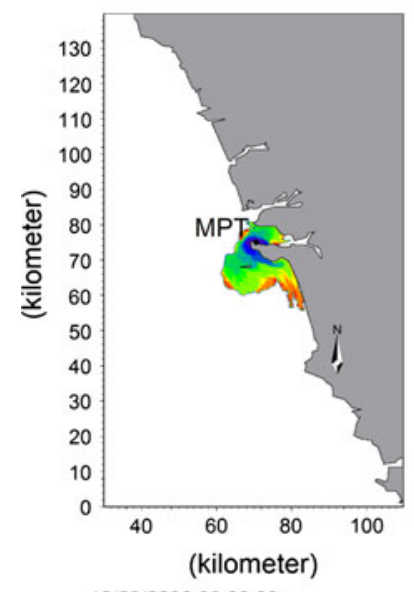

12/20/2006 00:00:00

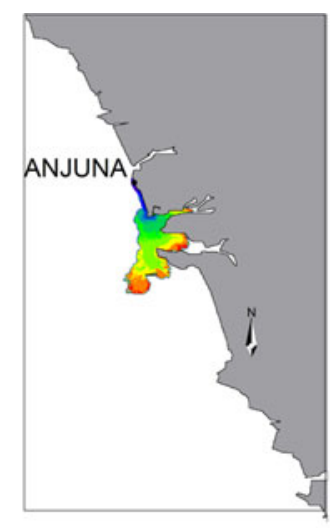

12/20/2006 00:00:00

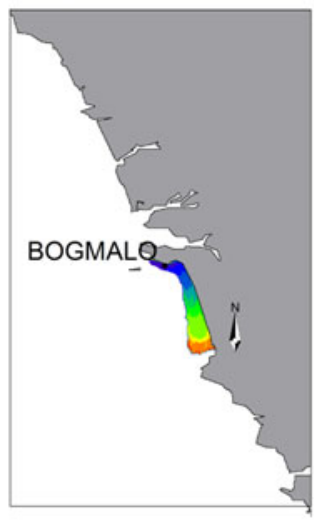

$12 / 20 / 200600: 00: 00$
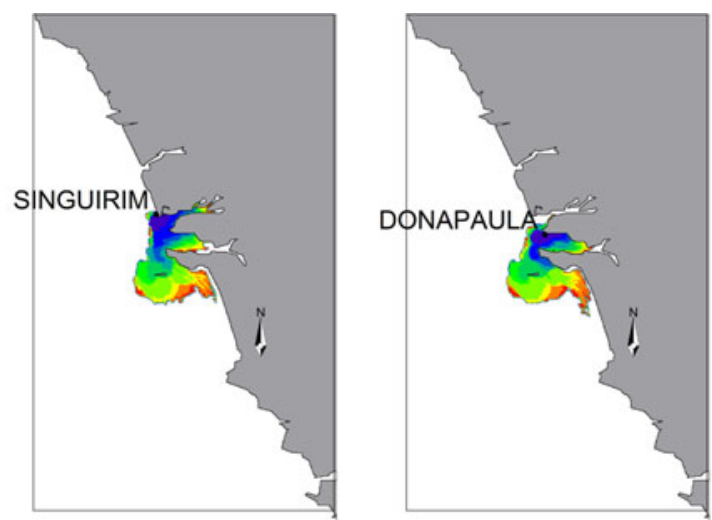

Time exposure DAYS

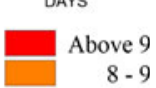

12/20/2006 00:00:00

12/20/2006 00:00:00
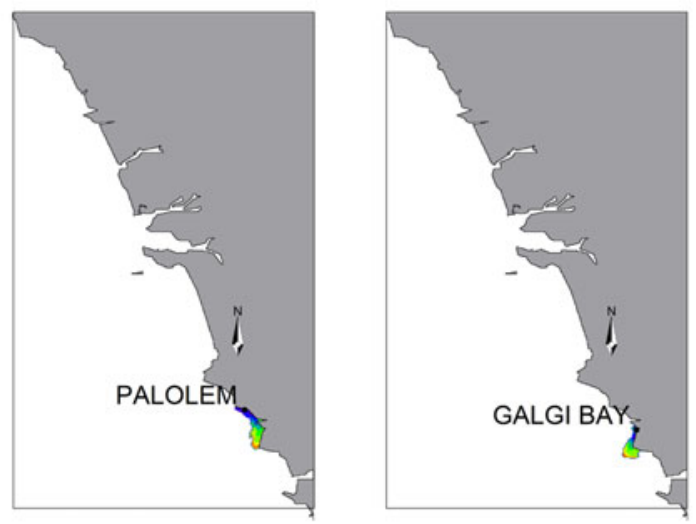

$7-8$

$6-7$

$5-6$

$4-5$

3- 4

$2-3$

$1-2$

$0-1$

Below 0

Fig. 4 Barnacle larval movement from major spawning sites during the NE monsoon season along the open coastal waters of the Goa region

waters of the study area vividly indicate that northern spawning sites are contributing to larval abundance in the estuary during December and May. But, with the reversing wind and current patterns in October, the larval abundance inside the estuary is contributed by the southern spawning sites (Table 1).

\subsection{Modelled and observed barnacle larval retention}

The results of the larval dispersion simulation carried out in the fine resolution domain (Figs. 7, 8, 9) indicate least retention of larvae in the estuary during the pre-monsoon period. This is also in concurrence with the observed field data (Fig. 2). There is higher abundance of larvae inside the estuary during the post-monsoon followed by the NE monsoon seasons. The larval movement is supported by the ebb and flood (Fig. 2). But higher larval abundance is noticed during the field measurements post-monsoon. A smaller retention of larvae has been observed in the Zuari estuary, and the larvae released from spawning sites were transported towards the Mandovi estuary during the NE monsoon and post-monsoon, as envisaged from the simulations. This could be the reason for higher larval abundance between the two high tides as larvae are retained within the estuary.

\section{Discussion}

Barnacles form large populations of adults on rocky shores and in estuaries which have the capacity to strongly affect the community structure through spatial interference completion (Hughes and Griffiths 1988; Wootton 1993; Queiroga et al. 2007). Recruitment may be broadly defined as the replenishment of a population with new individuals due to the process of reproduction and growth. For marine species with indirect development, recruitment involves several steps: larval development, dispersal during development, supply to appropriate settlement habitats, settlement and juvenile development (Queiroga et al. 2007). The model results indicate that the presence of barnacle larvae in the estuary is more or less controlled by spawning sites in the outer estuarine areas, as there is a clear presence of larvae coming from other sites and settling in the estuary. 


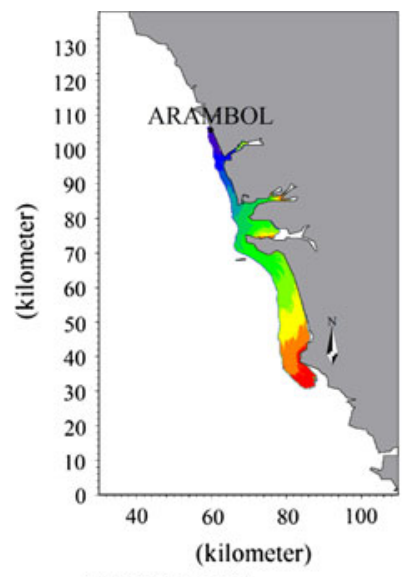

05/16/2007 00:00:01

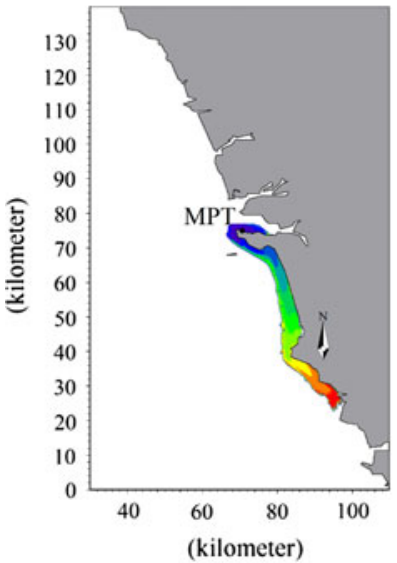

05/16/2007 00:00:01

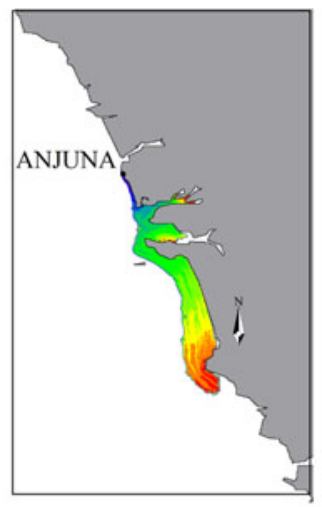

05/16/2007 00:00:01

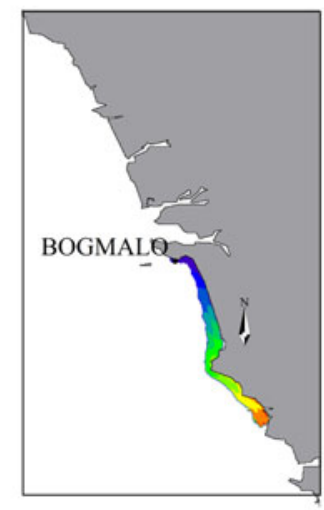

05/16/2007 00:00:01
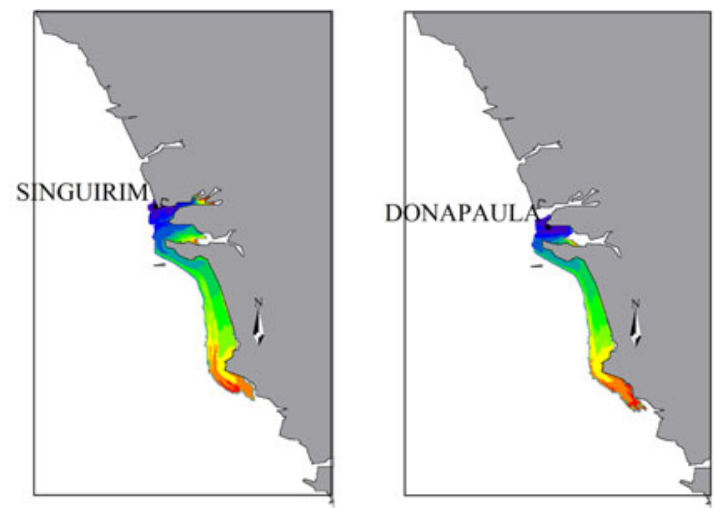

Time exposure DAYS

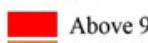

$8-9$

$7-8$

$6-7$

$5-6$

$4-5$

$3-4$

$2-3$

$1-2$

$0-1$

Below 0

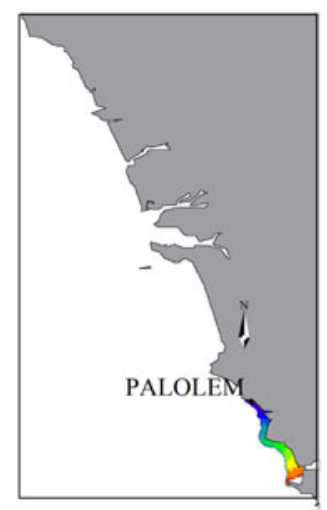

05/16/2007 00:00:01

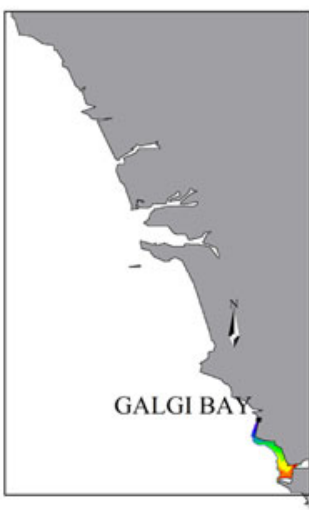

05/16/2007 00:00:01

Fig. 5 Barnacle larval movement from major spawning sites during the pre-monsoon season along the open coastal waters of the Goa region

Table 1 Distances traversed by modelled larvae from major spawning sites along the coastal waters of Goa during December 2006 and May and October 2007

\begin{tabular}{|c|c|c|c|c|}
\hline $\begin{array}{l}\text { Distance (in } \\
\text { Spawning } \\
\text { location }\end{array}$ & $\begin{array}{l}\mathrm{km}) \text { of } \\
\text { Dec } \\
11-28, \\
2006\end{array}$ & $\begin{array}{l}\text { Irval dis } \\
\text { May } \\
7-24, \\
2007\end{array}$ & $\begin{array}{l}\text { ersal } \\
\text { Sep 4- } \\
\text { Oct 11, } \\
2007\end{array}$ & Remarks \\
\hline Arambol & 38 & 78 & 22 & \multirow{4}{*}{$\begin{array}{l}\text { Larval transport is } \\
\text { southward during Dec } \\
2006 \text { and May 2007, in } \\
\text { accordance with the } \\
\text { predominant wind } \\
\text { direction. }\end{array}$} \\
\hline Anjuna & 32 & 64 & 35 & \\
\hline Singuirim & 25 & 57 & 42 & \\
\hline $\begin{array}{l}\text { Dona } \\
\text { Paula }\end{array}$ & 25 & 56 & $\begin{array}{c}45 \text { and } \\
13\end{array}$ & \\
\hline MPT & 17 & 53 & $\begin{array}{c}43 \text { and } \\
16\end{array}$ & \multirow{4}{*}{$\begin{array}{l}\text { In October 2007, stations } \\
\text { northward up to } \\
\text { Singuirim show a } \\
\text { northward transport but } \\
\text { the remaining stations } \\
\text { show } \mathrm{N}-\mathrm{S} \text { transport with } \\
\text { the predominant } \\
\text { transport being } \\
\text { northward. }\end{array}$} \\
\hline Bogmalo & 26 & 46 & $\begin{array}{c}50 \text { and } \\
16\end{array}$ & \\
\hline Palolem & 14 & 24 & $\begin{array}{c}10 \text { and } \\
6\end{array}$ & \\
\hline Galgibagh & 10 & 16 & $\begin{array}{c}12 \text { and } \\
2\end{array}$ & \\
\hline
\end{tabular}

However, the sites contributing to this abundance vary seasonally.

The model results for December, May and October (Figs. 7, 8, 9) are consistent with the field observations (Fig. 2), but in October showed high field values. The quantum of larvae reaching the estuary in the model results during the field sampling dates (Fig. 10a-c) indicate that the seasonal spawning sites are relevant to the abundance of barnacle larvae at the sampling point. The larval population in the estuary is well mixed and the geographical barriers are playing only a very limited role in their retention; hydrodynamics is the major driving force to their transport.

It is likely that the spawning sites may vary remarkably from the modelled sites. Any stony substratum-inhabiting barnacles may also form a source of the larvae. It may be noted that a study carried out in the laboratory showed the minimum age of barnacles releasing larvae as 28 days (Desai et al. 2006). The active reproduction in barnacles is protracted over the entire year with a lull during the SW 


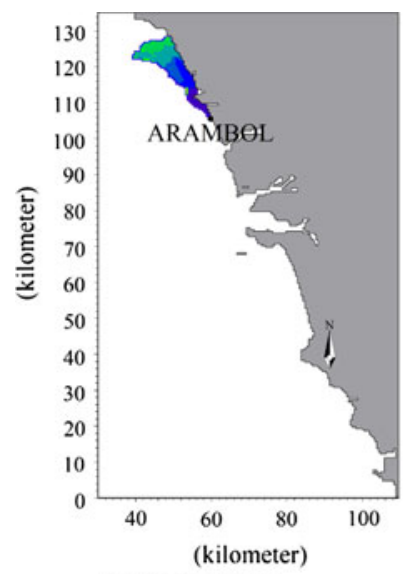

10/03/2007 00:00:00

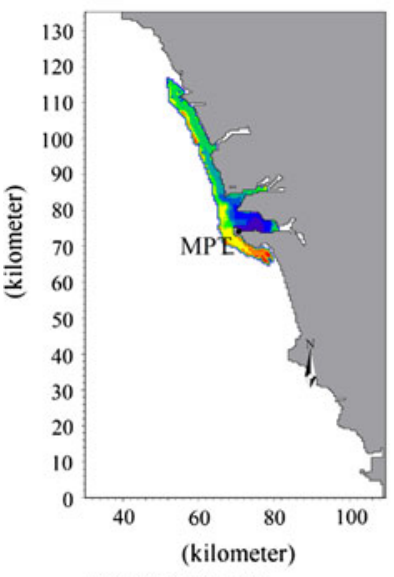

10/03/2007 00:00:00
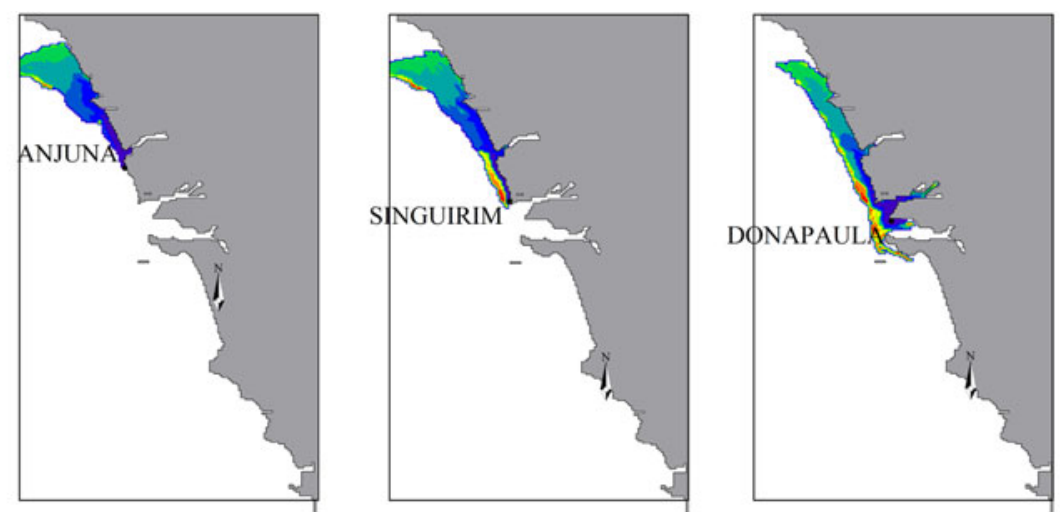

10/03/2007 00:00:00

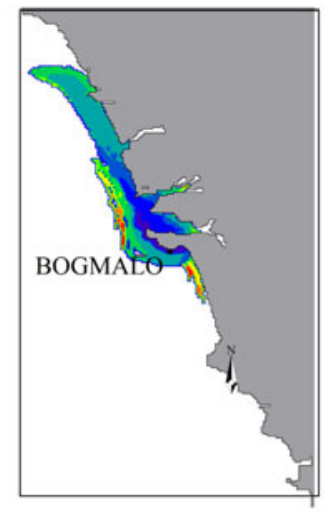

10/03/2007 00:00:00

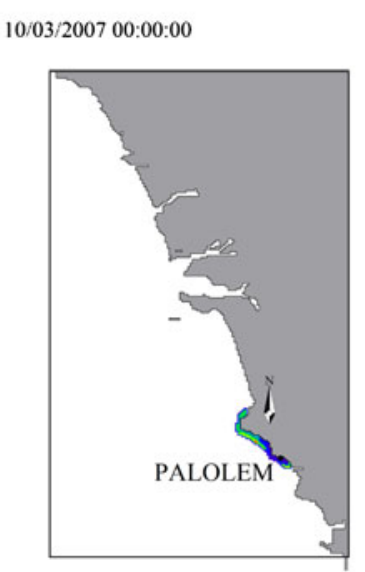

10/03/2007 00:00:00

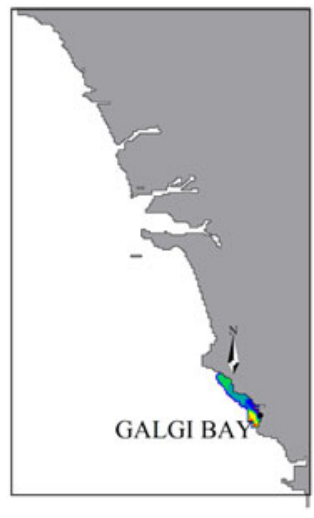

10/03/2007 00:00:00

10/03/2007 00:00:00
Time exposure DAYS

Above 9

$8-9$

$7-8$

$6-7$

$5-6$

$4-5$

$3-4$

$2-3$

$1-2$

$0-1$

Below 0

Fig. 6 Barnacle larval movement from major spawning sites during the post-monsoon period along the open coastal waters of the Goa region

monsoon season; however, the maximum larval abundance was observed during September to November. This was observed in the spawning area inhabited by a dominant barnacle Balanus amphitrite (Desai and Anil 2005; Desai et al. 2006). With several spawning sites of barnacles existing in the study area, input of nauplii from the gravid individuals from all the spawning sites will have an impact on the settlement and recruitment of new populations. However, there is no distinct pattern of spawning over an annual cycle. The maximum percentage of the barnacle Balanus amphitrite with ripe ovaries were observed during the post-monsoon and early pre-monsoon months (Desai et al. 2006), indicating higher density of these nauplii during these seasons. October is a month supported by spawning sites from the south, while the flow apparently supports the larval release from Dona Paula for the months of December and May. The relatively higher abundance of barnacle larvae in October can also be attributed to other factors such as rainfall, location of spawning and stock abundance, which are not considered in the present study. Unprecedented precipitation followed by a sunny day, and spawning from a site other than the rocky shore, such as a cement pillar or anchored vessel, may give rise to erroneous comparisons. This indicates the relevance of repeated time-series sampling to confirm the larval transport process. The AWS field measurements and hydrodynamic model result in the study region during October indicate favorable wind and current patterns, corroborating the view that more barnacle larvae are transported to the estuary from the southern sites (Fig. 11).

The release of larvae mostly coincides with high tide, and newly released nauplii and subsequent stages depend on the flow of water. The modelled (Figs. 7, 8, 9) and observed patterns of larval dispersion (Fig. 2) along the coast are similar in December and May. Qualitatively, we are able to interpret their abundance in a region, based on their dispersion characteristics. Larvae accumulate in the spawning site near Dona Paula during October. The abundance is comparatively less in May than December with a wider dispersal pattern. But for October, a sampling away from the dispersal core reflected a lesser abundance as the larvae may not be spreading up to that point. The dispersal core or spawning site is very relevant in this month as the dispersal zone is narrow. Therefore, a slight 

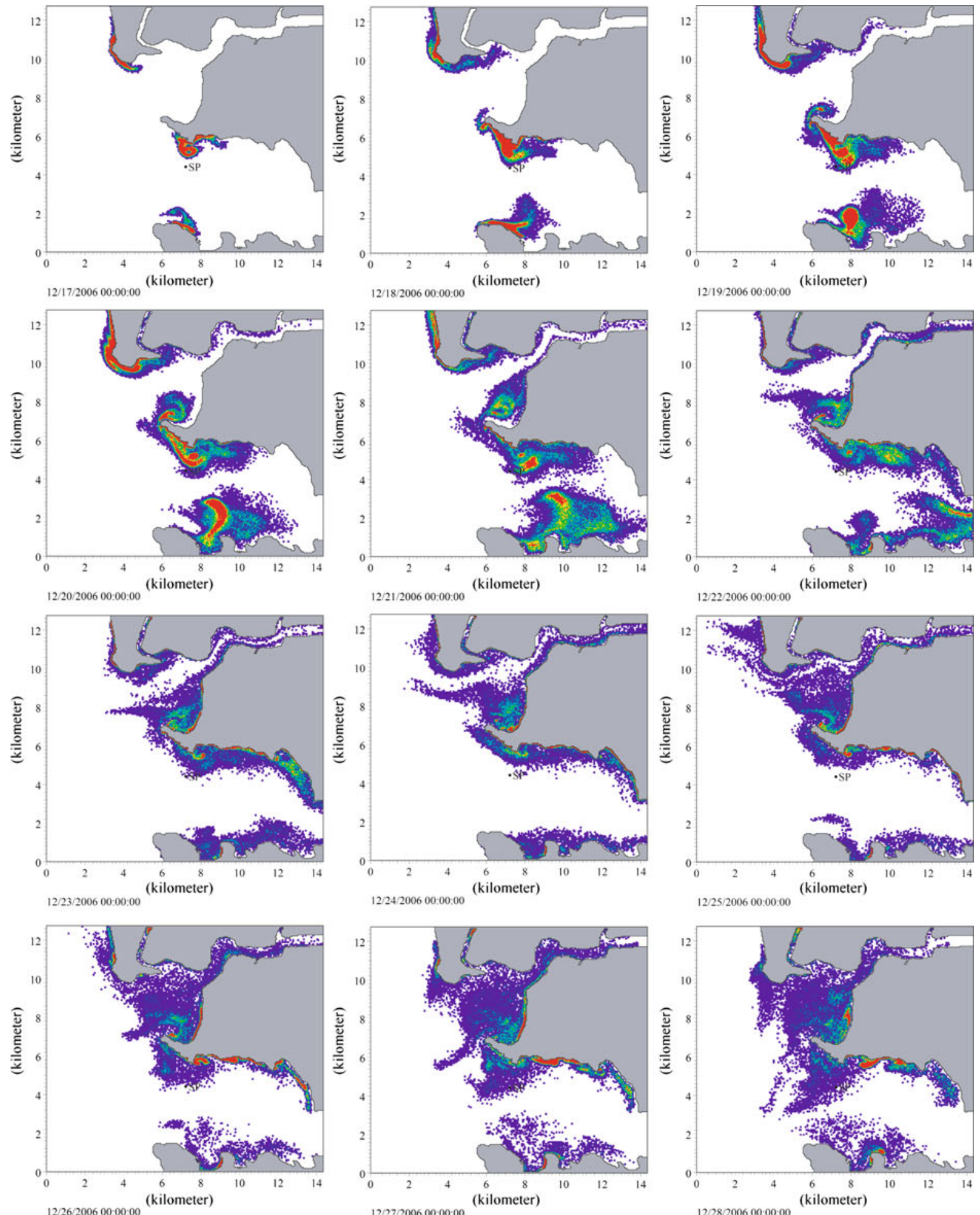

I.Conc. [kg/m3] (meter)

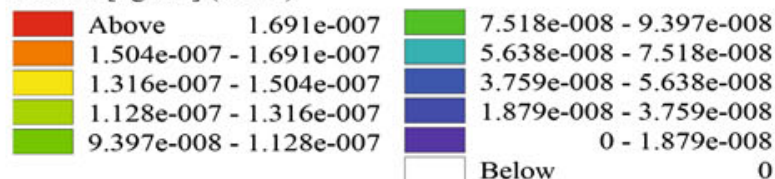

Fig. 7 Barnacle larval movement from major spawning sites during the NE monsoon season inside the Mandovi-Zuari esutuary 

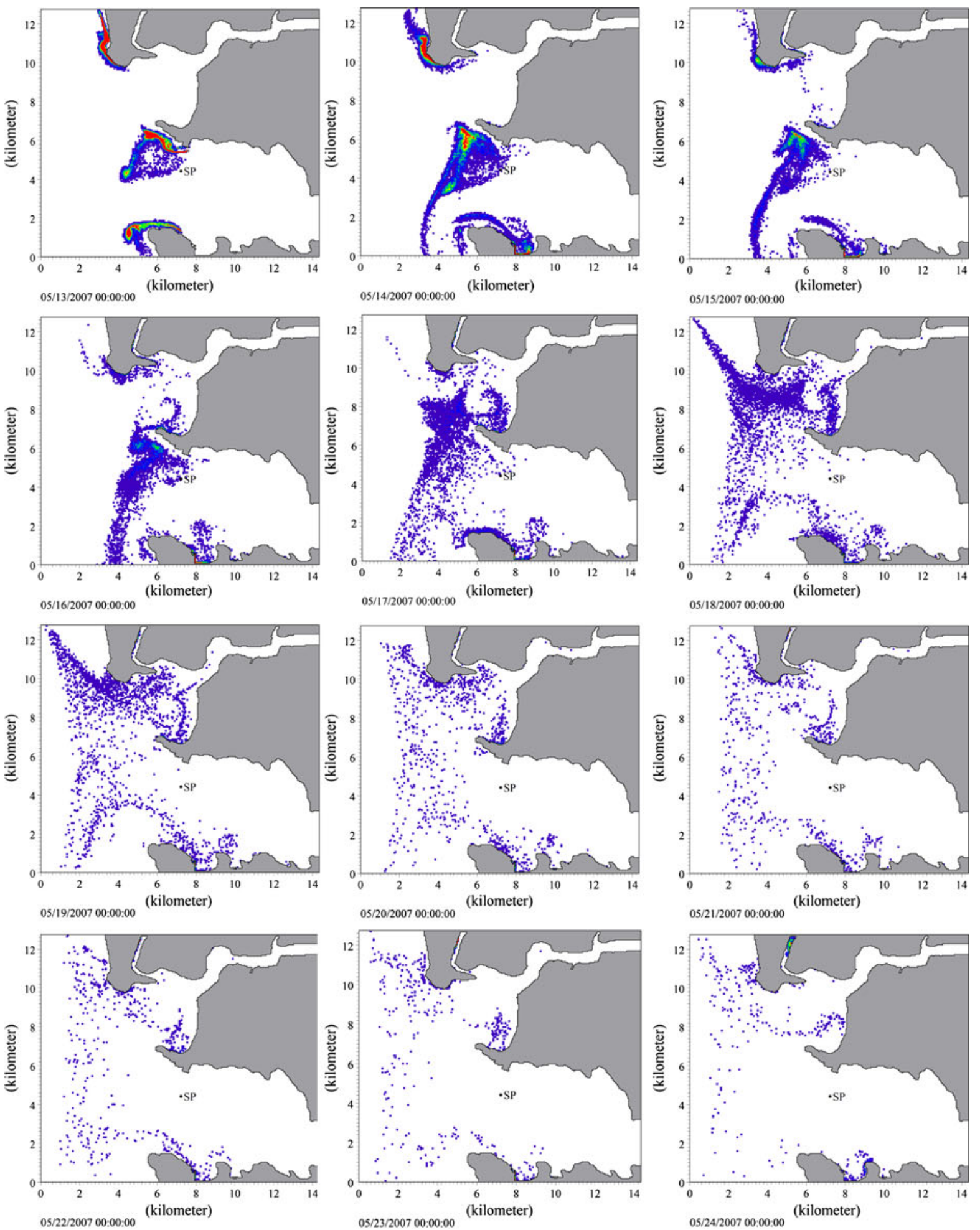

I.Conc. [kg/m3] (meter)

\begin{tabular}{|c|c|}
\hline $1.691 \mathrm{e}-007$ & \\
\hline $1.504 \mathrm{e}-007-1.691 \mathrm{e}-007$ & $5.638 \mathrm{e}-008-7.518 \mathrm{e}-008$ \\
\hline $1.316 \mathrm{e}-007-1.504 \mathrm{e}-007$ & $3.759 \mathrm{e}-008-5.638 \mathrm{e}-008$ \\
\hline $1.128 \mathrm{e}-007-1.316 \mathrm{e}-007$ & $1.879 \mathrm{e}-008-3.759 \mathrm{e}-008$ \\
\hline $9.397 \mathrm{e}-008-1.128 \mathrm{e}-007$ & $0-1.879 \mathrm{e}-008$ \\
\hline $7.518 \mathrm{e}-008-9.397 \mathrm{e}-008$ & Below \\
\hline
\end{tabular}

Fig. 8 Barnacle larval movement from major spawning sites during the pre-monsoon season inside the Mandovi-Zuari esutuary 

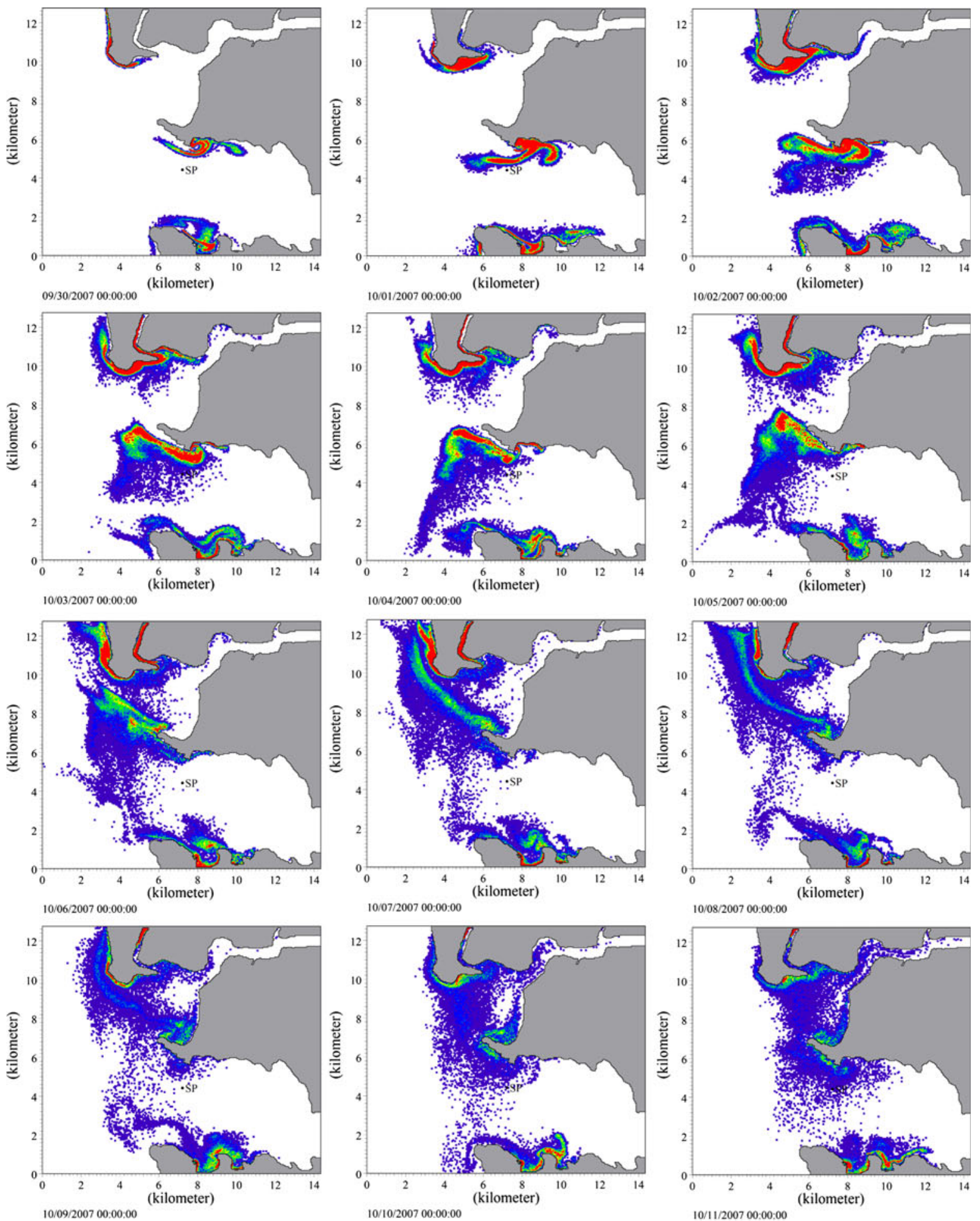

I.Conc. $[\mathrm{kg} / \mathrm{m} 3]$ (meter)

\begin{tabular}{|c|c|}
\hline $1.691 \mathrm{e}-007$ & \\
\hline $1.504 \mathrm{e}-007-1.691 \mathrm{e}-007$ & $5.638 \mathrm{e}-008-7.518 \mathrm{e}-008$ \\
\hline $1.316 \mathrm{e}-007-1.504 \mathrm{e}-007$ & $3.759 \mathrm{e}-008-5.638 \mathrm{e}-008$ \\
\hline $1.128 \mathrm{e}-007-1.316 \mathrm{e}-007$ & $1.879 \mathrm{e}-008-3.759 \mathrm{e}-008$ \\
\hline $9.397 \mathrm{e}-008-1.128 \mathrm{e}-007$ & $0-1.879 \mathrm{e}-008$ \\
\hline $7.518 \mathrm{e}-008-9.397 \mathrm{e}-008$ & Below \\
\hline
\end{tabular}

Fig. 9 Barnacle larval movement from major spawning sites during the post-monsoon season inside the Mandovi-Zuari esutuary 


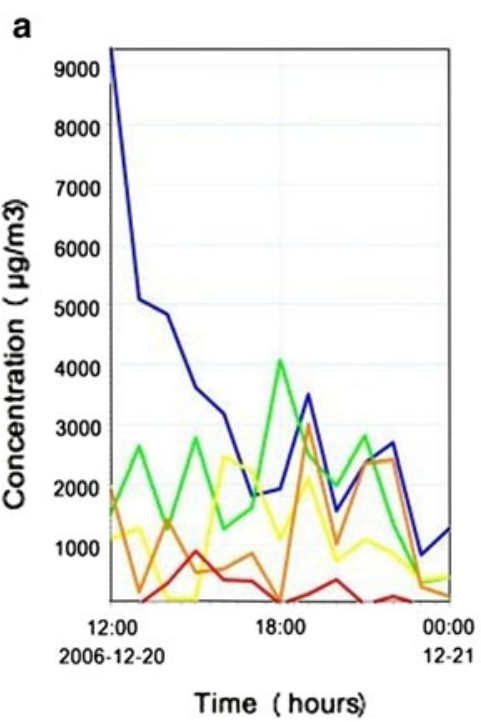

Time (hours) b

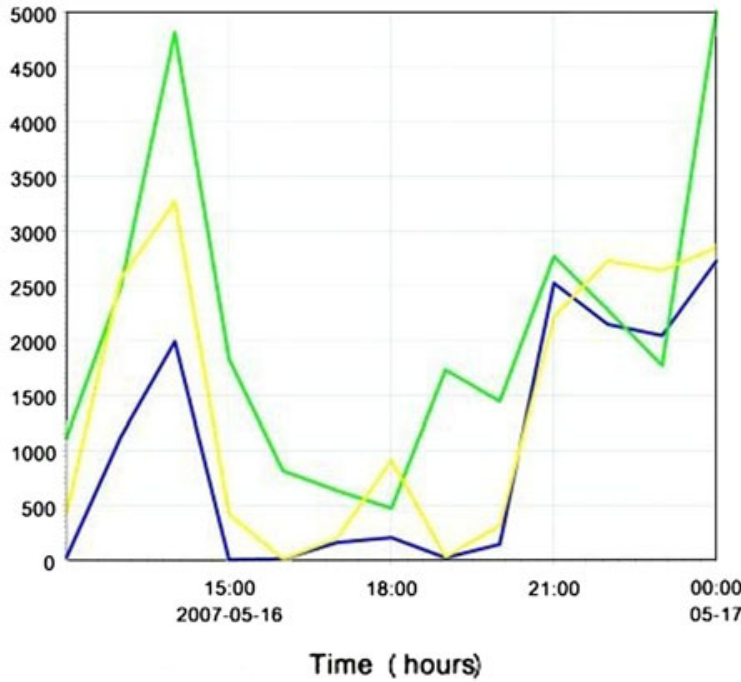

C

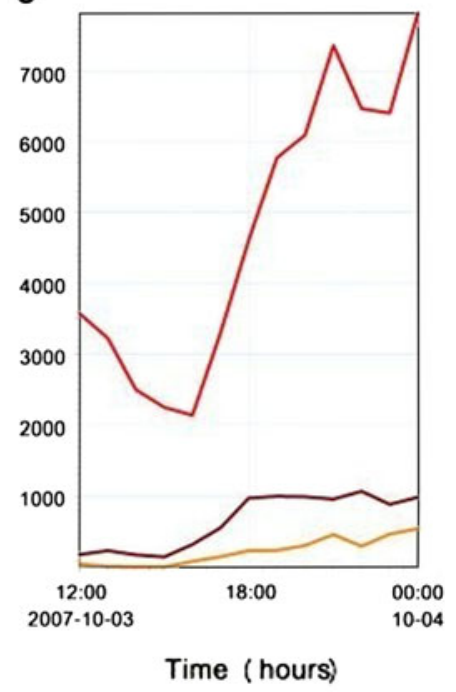

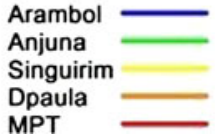

\section{Arambol}

Anjuna

Singuirim

Fig. 10 Concentration of larvae reaching the sampling point inside the estuary from major spawning sites during a NE monsoon, $\mathbf{b}$ pre-monsoon and $\mathbf{c}$ post-monsoon seasons

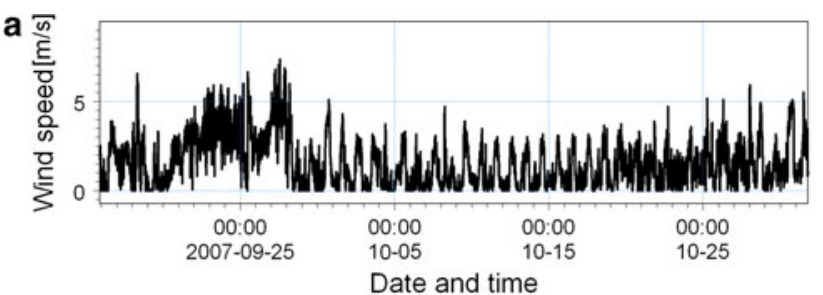

b
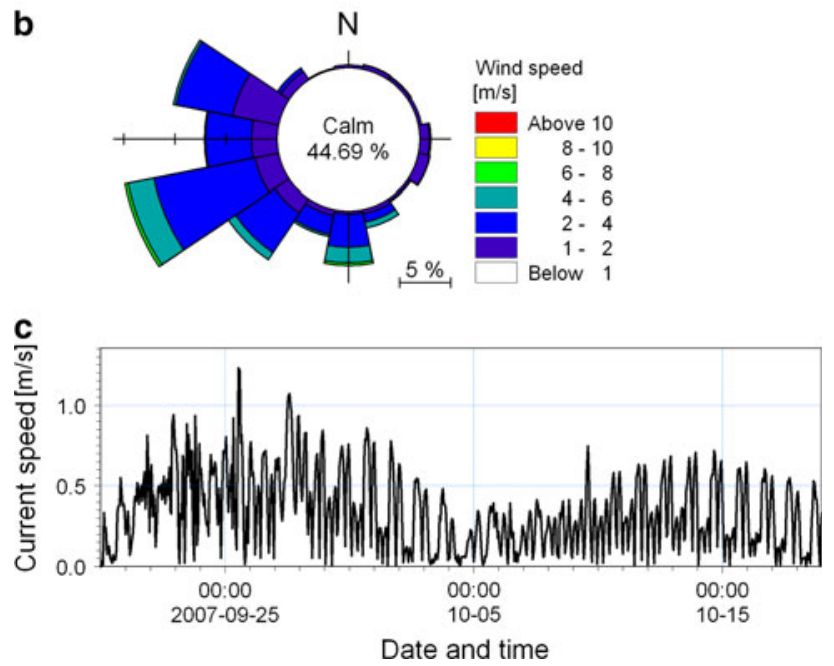

Fig. 11 a Wind speed and direction, $\mathbf{b}$ wind rose and $\mathbf{c}$ current speed and direction during the post-monsoon season

change in the spawning site will reflect a major change in the larval availability at a particular point. The simulated tide and current explains the possible transport of larvae
(Table 1) along with changing hydrodynamics. Tidal fronts, which have been correlated to larval accumulation, occur in shallow but not in deep waters (Epifanio 1988; Clancy and Epifanio 1989). It can be pointed out that larval return to open-coast habitat can potentially occur passively by eddy diffusion from an offshore larval pool to shallow water, semi-continuous advection and advective transporting events, which may involve vertical swimming behavior, while active transport can potentially be achieved through swimming shorewards (Pineda 2000).

Compared to the larvae of organisms living in the open coast, estuarine organisms still have to solve an extra problem after having been transported to the near-shore environment, that is discovering estuarine inlets and travel streams. The currently accepted view is that invertebrate and fish larvae migrate into estuaries using selective tidal stream transport (Forward and Tankersley 2001). During upstream selective tidal stream transport, larvae settle on or move close to the bottom during ebb tides to avoid being displaced seaward or ascend in the water column during flood tides (Queiroga et al. 2007).

An offshore field sampling of barnacle larvae outside the estuarine domain clearly indicated a lesser abundance of larvae. The samples were collected from off Goa $\left(15^{\circ} 26^{\prime} \mathrm{N}\right.$, $73^{\circ} 44^{\prime} \mathrm{W}$ ) on 4 March and 10 October 2005 , and on 16 January 2006. The methods followed for the collection of samples were similar to those given in Sect. 2.5. The average abundance of larvae which was collected from the offshore domain during 3 different sampling periods was 
$474( \pm 664)$ larvae per $100 \mathrm{~m}^{3}$, which is much lower than the larval abundance within the estuary. Alvarez et al. (1990) illustrated through their study that along-shore advection was on an average ten times stronger than the cross-shore advection. This corroborates our numerical experiments that the larval spread is only in the coastal and estuarine waters unlike a pelagic offshore larval pool in the case of the Californian barnacle (Pineda 2000). Marine invertebrate larvae of non-decapods are generally small and have limited swimming ability (Chia et al. 1984), and therefore these larvae must probably be transported back by advection (Okubo 1994). It is also suggested that swimming is unimportant for most of the marine invertebrate species (Shanks 1995), although it is a possibility for certain larger decapod larvae and other large short-lived larvae (Olson 1985; Pineda 2000).

\section{Conclusions}

The barnacle population abundance is contributed by spawning sites outside the estuary and the sites contributing to the barnacle larval abundance vary from season to season. Spawning sites found on the north of the estuary supply barnacle larvae to the estuary during all seasons except post-monsoon. The barnacle larval population in the estuary is well mixed, with spawning sites located north and south of the estuary contributing to the larval abundance. Larvae traverse as much as $78 \mathrm{~km}$ along the coastal waters with a minimum dispersal of $3-5 \mathrm{~km}$.

Barnacle larval abundance is higher post-monsoon as large quantities of larvae are supplied from spawning sites located to the south of the estuary. This is further strengthened by high flood currents. Unlike the pelagic open offshore larval pool for barnacles on the Californian coast (Pineda 2000), the acorn barnacle larvae are concentrated only in the near-shore waters and the estuarine mouth, as seen in the observations and numerical experiments.

Acknowledgments The authors wish to thank the director of the National Institute of Oceanography (NIO), Goa, for support. The first author would like acknowledge the initial CSIR-JRF support and the support from the Director, Central Agricultural Research Institute (CARI), Port Blair, in the later phase for the completion of this work. The current measurements were made available for the study by Shri. Sidharth S Ghatkar and the help received in modelling from Shri. K. Sudheesh and Dr. M.T. Babu is greatly acknowledged. This is NIO contribution number 5408.

\section{References}

Aiken CM, Navarrete SA, Castillo MI, Castilla JC (2007) Alongshore larval dispersal kernels in a numerical ocean model of the central Chilean coast. Mar Ecol Prog Ser 339:13-24
Alvarez LG, Godinez VM, Lavin MF (1990) Diepersion en la franja costera de Tijuana \& Baja California. ear shore dispersion off Tijuana. Baja California. Ciencias Marinas (In Spanish and English) 16:87-109

Anil AC (1986) Studies on marine biofouling in the Zuari estuary (Goa) west coast of India. PhD thesis, University of Karnataka

Anil AC, Kurian J (1996) Influence of food concentration, temperature and salinity on the larval development of Balanus amphitrite. Mar Biol 127:115-124

Anil AC, Dattesh D, Lidita K (2001) Larval development and metamorphosis in Balanus amphitrite Darwin (Cirripedia: Thoracica): significance of food concentration, temperature and nucleic acids. J Exp Mar Biol Ecol 263:125-141

Anonymous (1930) Tides and harmonic constants. Special Publication No. 26. International Hydrographic Bureau, Monaco

Aparna M, Shetye SR, Shankar D, Shenoi SSC, Mehra P, Desai RGP (2005) Estimating the seaward extent of sea breeze from QuikSCAT scatterometry. Geophys Res Lett 32:L13601. doi: 10.1029/2005GL023107

Babu MT, Vethamony P, Desa E (2005) Modelling tide-driven currents and residual eddies in the Gulf of Kachchh and their seasonal variability a marine environmental planning perspective. Ecol Model 184:299-312

Black KP, Gay SL, Andrews JC (1990) Resident times of neutrally buoyant matter such as larvae, sewage or nutrients on coral reefs. Coral Reefs 9:105-114

Boicourt WC (1982) Estuarine larval retention mechanisms on two scales. In: Kennedy VS (ed) Estuarine comparisons. Academic, New York, pp 445-457

Chia FS, Buckland-Nicks J, Young CM (1984) Locomotion of marine invertebrate larvae: a review. Can J Zool 62:1205-1222

Chubarenko IP, Tchepikova I (2001) Modelling of man-made contribution to salinity increase into the Vistula Lagoon (Baltic Sea). Ecol Model 138:87-100

Clancy M, Epifanio CE (1989) Distribution of crab larvae in relation to tidal fronts in Delaware Bay, USA. Mar Ecol Prog Ser 57:77-82

Cowen RK, Sponaugle S (2009) Larval dispersal and marine population connectivity. Annu Rev Mar Sci 1:443-466

Cowen RK, Paris CB, Srinivasan A (2006) Scales of connectivity in marine populations. Science 311:522-527

Desai DV, Anil AC (2004) Impact of food type, temperature and starvation on larval development of Balanus amphitrite Darwin (Cirripedia: Thoracica). J Exp Mar Biol Ecol 306:113-137

Desai DV, Anil AC (2005) Recruitment of the barnacle Balanus amphitrite in a tropical estuary: implications of environmental perturbation, reproduction and larval ecology. J Mar Biol Assoc UK 85:909-920

Desai DV, Prakash S (2009) Physiological responses to hypoxia and anoxia in Balanus amphitrite (Cirripedia: Thoracica). Mar Ecol Prog Ser 390:157-166

Desai DV, Anil AC, Venkat K (2006) Reproduction in Balanus amphitrite Darwin (Cirripedia: Thoracica): influence of temperature and food concentration. Mar Biol 149:1431-1441

DHI (2001) User Guide and Reference Manual for MIKE21. Danish Hydraulic Institute, Denmark

Dyer KR (1979) Estuarine hydrography and sedimentation: a handbook. Cambridge University Press, Cambridge

Epifanio CE (1988) Transport of invertebrate larvae between estuaries and the continental shelf. Am Fish Soc Symp 3:104-114

Fiksen Ø, Jørgensen C, Kristiansen T, Vikebø F, Huse G (2007) Linking behavioural ecology and oceanography: larval behaviour determines growth, mortality and dispersal. Mar Ecol Prog Ser 347:195-205

Forward RB Jr, Tankersley RA (2001) Selective tidal-stream transport of marine animals. Ocean Mar Biol Annu Rev 39:305-353 
Gaines SD, Bertness M (1992) The dynamics of juvenile dispersal: why field ecologists must integrate. Ecology 74:2430-2435

Gaonkar CA, Samiksha SV, George G, Aboobacker VM, Vethamony P, Anil AC (2012) Numerical simulations of barnacle larval dispersion coupled with field observations on larval abundance, settlement and recruitment in a tropical monsoon influenced coastal marine environment. J Mar Syst 94:218-231

George G, Vethamony P, Sudheesh K, Babu MT (2011) Fish larval transport in a macro-tidal regime: Gulf of Kachchh, west coast of India. Fish Res 110:160-169

Hughes RN, Griffiths CL (1988) Self-thinning in barnacles and mussels - the geometry of packing. Am Nat 132:484-491

James MK, Armsworth PR, Mason LB, Bode L (2002) The structure of reef fish meta populations: modelling larval dispersal and retention patterns. Proc R Soc Lond B 269:2079-2086

Jessopp MJ (2007) The quick and the dead: larval mortality due to turbulent tidal transport. J Mar Biol Assoc UK 86:675-680

Kinlan BP, Gaines SD (2003) Propagule dispersal in marine and terrestrial environments: a community perspective. Ecology 84:2007-2020

Kinlan BP, Gaines SD, Lester SE (2005) Propagule dispersal and the scales of marine community process. Divers Distrib 11:139-148

Kunte P, Wagle BC, Yasushio S (2000) Remote assessment of net shore drift along the west coast of India. PORSEC Proc 2:685-689

Lobel PS, Robinson AR (1986) Transport and entrapment of fish larvae by ocean mesoscale eddies and currents in Hawaiian waters. Deep Sea Res 33:483-500

Manoj NT, Unnikrishnan AS (2009) Tidal circulation and salinity distribution in the Mandovi and Zuari estuaries: case study. J Waterw Port Coast Ocean Eng 135(6):278-287

Murdoch RC (1989) The effects of headland eddy on surface macrozooplankton assemblages north of Otago Peninsula, New Zealand. Estuar Coast Shelf Sci 29:361-383

Neetu S, Shetye SR, Chandramohan P (2006) Impact of sea-breeze on wind-seas off Goa, west coast of India. J Earth Syst Sci 115(2):229-234

Okubo A (1994) The role of diffusion and related physical processes in dispersal and recruitment of marine population. In: Sammarco PW, Heron ML (eds) The Bio-physics of marine larval dispersal, vol 45. American Geophysics Union, Washington, D.C. pp 5-32

Olson RR (1985) The consequences of short-distance larval dispersal in a sessile marine invertebrate. Ecology 66:30-39

Palumbi SR (2003) Population genetics, demographic connectivity and the design of marine protected areas. Ecol Appl 13:S146S158

Peterson EW, Hennessey JP (1978) On the use of power laws for estimates of wind power potential. J Appl Meteorol Climatol 17:390-394

Pineda J (2000) Linking larval settlement to larval transport: assumptions, potentials, and pitfalls. Oceanogr East Pac pp 84-105
Queiroga H, Cruz T, dos Santos A, Dubert J, González-Gordillo JI, Paula J, Peliz A, Santos AMP (2007) Oceanographic and behavioural processes affecting invertebrate larval dispersal and supply in the western Iberia upwelling ecosystem. Prog Oceanogr 74:174-191

Roff JC, Pett RJ, Rogers GF, Budgell WP (1979) A study of plankton ecology in Chesterfield Inlet, Northwest Territories: an arctic estuary. In: Kennedy VS (ed) Estuarine perspectives, vol 2. Academic, New York, pp 185-197

Sammarco PW, Andrews JC (1988) Localized dispersal and recruitment in Great Barrier Reef corals: the Helix experiment. Science 239:1422-1424

Seed R, Suchanek TH (1992) Population and community ecology of Mytilus. In: Gosling E (eds) The mussel Mytilus: ecology, physiology, genetics and culture. Development in aquaculture and fisheries sciences, vol 25. Elsevier, Amsterdam, pp 87-169

Shankar D, Shetye SR (2001) Why is mean sea level along the Indian coast higher in the Bay of Bengal than in the Arabian Sea? Geophys Res Lett 28:563-565

Shanks AL (1995) Mechanisms of cross-shelf dispersal of larval invertebrates and fish. In: McEdward L (ed) Ecology of marine invertebrate larvae. CRC, Boca Raton, pp 323-367

Shanks AL (2009) Pelagic larval duration and dispersal distance revisited. Biol Bull 216:373-385

Shetye SR, Murty CS (1987) Seasonal variation of the salinity in Zuari Estuary, Goa, India. Proc Indian AS-Earth 96:249-257

Shetye SR, Gouveia AD, Shenoi SSC, Micheal GS, Sundar D, Almeida AM, Santanam K (1991) The coastal current off western India during the northeast monsoon. Deep Sea Res 38:1517-1529

Shetye SR, Gouveia AD, Singbal SY, Naik CG, Sunder D, Michael GS, Nampoothiri G (1995) Propagation of tides in the Mandovi and Zuari Estuarine Network. Proc Indian AS-Earth 104:667-682

Stephens SA, Broekhuizen N, Macdiarmid AB, Lundquist CJ, McLeodand L, Haskew R (2006) Modelling transport of larval New Zealand abalone (Haliotisiris) along an open coast. Mar Freshw Res 57:519-532

Thiebaut E, Dauvin JC, Lagadeuc Y (1994) Horizontal distribution and retention of Owenia fusiformis larvae (Annelida: Polychaeta) in the bay of Seine. J Mar Biol Assoc UK 74:129-142

Unnikrishnan AS, Shetye SR, Gouveia AD (1997) Tidal propagation in Mandovi and Zuari Estuarine network, West Coast of India: impact of fresh water influx. Estuar Coast Shelf Sci 45:737-744

Unnikrishnan AS, Gouveia AD, Vethamony P (1999) Tidal regime in Gulf of Kachch west coast of India by 2D model. J Waterw Port Coast Ocean Eng 1256:276-284

Wolanski E, Hamner WM (1988) Topographically controlled fronts in the ocean and their biological influence. Science 241:177-181

Wootton JT (1993) Indirect effects and habitat use in an intertidal community-interaction chains and interaction modifications. Am Nat 141:71-89 